\title{
Geometric perturbations in multiheaded papillary tip positions associated with acute ovine ischemic mitral regurgitation
}

\author{
Tomasz A. Timek, MD, ${ }^{a}$ David T. Lai, MD, ${ }^{\mathrm{b}}$ Wolfgang Bothe, MD, ${ }^{\mathrm{b}}$ David Liang, MD, PhD, \\ George T. Daughters, MS, ${ }^{\text {,d }}$ Neil B. Ingels, PhD, ${ }^{\text {,d }}$ and D. Craig Miller, MD
}

\begin{abstract}
Background: Novel surgical approaches are focusing on the "ventricular disease" of ischemic mitral regurgitation (IMR), to correct altered papillary muscle (PM) tip positions (apical displacement) and ameliorate leaflet tethering. Due to the anatomic complexity of the subvalvular apparatus, however, the precise geometric perturbations of the multiheaded PM tips associated with IMR remain uncharacterized.

Methods: In 6 adult sheep, we implanted 3 markers on each PM. To specifically identify distinct PM tips, 1 marker was placed on the PM origin of the dominant chord to the anterior, posterior, and commissural leaflets. Nine markers were placed on the edge of the posterior mitral leaflet, and 5 on the edge of the anterior mitral leaflet. Eight markers were sewn around the mitral annulus. Animals were studied immediately postoperatively, with biplane videofluoroscopy and transesophageal echocardiography, before and during acute snare occlusion of the proximal left circumflex coronary artery, to induce IMR. Papillary muscle tip and leaflet edge geometry was expressed as the orthogonal distance of each respective marker to the least-squares mitral annulus plane at end-systole. In addition, the distance from each PM tip marker to the mitral annulus "saddle horn" was calculated.
\end{abstract}

Results: Acute left circumflex occlusion significantly increased mitral regurgitation from a baseline of $0.7 \pm 0.3$ to $2.5 \pm 0.5(P<.05)$. The IMR was associated with posterior leaflet restriction near the central leaflet edge, with simultaneous prolapse of both leaflets near the posterior commissure. No apical displacement of PM tips was observed during IMR, although the posterior PM moved farther away from the midseptal annulus.

Conclusions: During acute ischemia, no apical displacement of any PM tip was observed. Posterior PM movement away from the annular saddle horn, and toward the annulus, was associated with IMR and leaflet prolapse near the posterior commissure, and with restriction near the valve center. These data may help guide development of surgical interventions aimed at PM repositioning. (J Thorac Cardiovasc Surg 2015;150:232-7)

\footnotetext{
From the ${ }^{\text {a Meijer }}$ Heart and Vascular Institute at Spectrum Health, Grand Rapids, Mich; ${ }^{b}$ Department of Cardiothoracic Surgery, ${ }^{c}$ Division of Cardiovascular Medicine, Stanford University School of Medicine, Stanford, Calif; and ${ }^{\mathrm{d}}$ Department of Cardiovascular Physiology and Biophysics, Research Institute of the Palo Alto Medical Foundation, Palo Alto, Calif.

This work was supported by grants HL-29589 and HL-48837 from the National Heart, Lung, and Blood Institute. Drs Lai, Bothe, and Timek were Carl and Leah McConnell Cardiovascular Research Fellows. Dr Timek was a recipient of the Thoracic Surgery Education and Research Foundation Fellowship Award.

Received for publication Dec 1, 2014; revisions received April 12, 2015; accepted for publication April 18, 2015; available ahead of print May 19, 2015.

Address for reprints: D. Craig Miller, MD, Department of Cardiothoracic Surgery, Falk Cardiovascular Research Center, Stanford University School of Medicine, Stanford, CA 94305-5247 (E-mail: dcm@stanford.edu).

0022-5223/\$36.00

Copyright (c) 2015 by The American Association for Thoracic Surgery

http://dx.doi.org/10.1016/j.jtcvs.2015.04.037
}

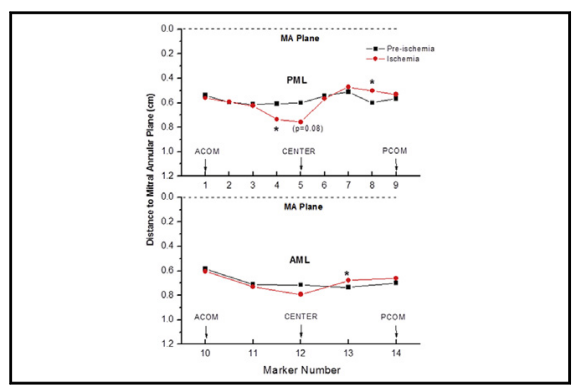

Mitral leaflet distance to annular plane before (squares) and during (circles) acute ischemic mitral regurgitation.

\section{Central Message}

Ovine ischemic mitral regurgitation was not associated with apical displacement of papillary muscle tips from the mitral annular plane.

\begin{abstract}
Perspective
Current data offer novel insight into papillary muscle position during acute IMR, and may better guide subvalvular reparative techniques. Precise tagging of papillary muscle tips and leaflets permitted mapping and identification of small but important spatial alterations of valvular structures. Correction of these perturbations may hold the promise of more durable repair of IMR.
\end{abstract}

See Editorial Commentary page 238.
Ischemic mitral regurgitation (IMR) represents the complex interplay of annular, subvalvular, and ventricular geometric perturbations that lead to valvular insufficiency in the absence of organic abnormalities. The "ventricular" disease of IMR is believed to arise mainly from postinfarction subvalvular remodeling and altered force distribution on the mitral apparatus. ${ }^{1}$ Displacement of papillary muscles (PMs) and resultant leaflet tethering lead to malcoaptation and valvular leakage. Traditional reparative approaches with undersized ring annuloplasty have yielded disappointing results, ${ }^{2}$ and subvalvular techniques have been sought, to improve repair durability and patient outcomes. Papillary 


\section{Abbreviations and Acronyms \\ $\mathrm{IMR}=$ ischemic mitral regurgitation \\ $\mathrm{PM}=$ papillary muscle \\ $3 \mathrm{D}=3$-dimensional}

muscle repositioning for the treatment of IMR has shown some promise in both experimental ${ }^{3}$ and clinical ${ }^{4}$ studies, yet the guiding principle of these interventions remains unclear.

Although apical PM displacement has been reported as the etiology of leaflet tethering in IMR, ${ }^{5,6}$ contrasting studies suggest little change in position ${ }^{7}$ and even basal displacement. ${ }^{8}$ The precise 3-dimensional (3D) geometric displacement of the PM tips associated with ischemic mitral insufficiency therefore needs further definition, especially in light of the variable anatomy of human PMs. To better guide how subvalvular geometry should be altered to best treat IMR, more data are needed on the precise geometric displacements of individual PM heads that are associated with IMR. Using an acute ovine model of IMR, we implanted a dense array of myocardial markers on the PMs and the mitral leaflets to elucidate the subvalvular perturbations that modulate leaflet malcoaptation and mitral insufficiency.

\section{METHODS}

\section{Surgical Preparation}

Six adult castrated male sheep were used in the study. The operative procedure for marker implantation has been described in detail previously. ${ }^{9}$ Myocardial markers of various shapes were implanted in a dense array on the mitral leaflet edges ( 9 on the posterior mitral leaflet edge, and 5 on the anterior mitral leaflet edge) and around the mitral annulus (8), as illustrated in Figure 1.

To specifically identify distinct PM tips, 1 marker was placed on the PM origin of the dominant chord to the anterior, posterior, and commissural leaflets (Figure 2). Thus, 3 markers were implanted on the anterior PM, and 3 on the posterior PM. Some variability was found in the papillary head anatomy, but the origins of the chords to anterior, posterior, and commissural leaflets could be identified without difficulty.

After completion of marker implantation, a silastic loop was placed around the proximal left circumflex coronary artery for induction of posterolateral ischemia and IMR. Subsequently, the heart was defibrillated, and the animal was weaned from cardiopulmonary bypass and transferred immediately to the experimental animal catheterization laboratory; there, the animal was studied while intubated, open-chest, and anesthetized with ketamine (1-4 mg/kg/hour intravenous infusion) and diazepam (5 mg intravenous bolus as needed). Simultaneous biplane videofluoroscopy, hemodynamic data recordings, and transesophageal color Doppler echocardiography were recorded before (preischemia) and during acute occlusion of proximal circumflex artery (ischemia) and IMR.

All animals received humane care in compliance with the "Principles of Laboratory Animal Care" formulated by the National Society for Medical Research and the "Guide for Care and Use of Laboratory Animals" prepared by the National Academy of Sciences and published by the National Institutes of Health (Department of Health, Education, and Welfare NIHG publication 85-23, revised 1985). This study was approved by the Stanford Medical Center Laboratory Research Animal Review Committee and conducted according to Stanford University policy.

\section{Data Acquisition and Analysis}

Data acquisition, ${ }^{10}$ digital transformation, ${ }^{11}$ and $3 \mathrm{D}$ reconstruction ${ }^{12}$ were performed as described previously. Two to three consecutive steady-state beats before and during induction of IMR were averaged and designated as "pre-ischemia" and "ischemia" data for each animal, respectively. "Pre-ischemia" was defined as steady-state hemodynamic conditions that were maintained for $\geq 5$ minutes before induction of acute circumflex artery occlusion. "Ischemia" was defined as acute circumflex coronary artery occlusion of 1 to 3 minutes, to induce significant mitral regurgitation (moderate or greater) on simultaneous transesophageal echocardiography. For each cardiac cycle, end-systole was defined as the frame containing the peak rate of fall of left ventricular pressure $(-\mathrm{dP} / \mathrm{dt})$; enddiastole was defined as the videofluoroscopic frame containing the peak of the electrocardiogram R-wave. Mitral regurgitation was graded subjectively, according to the extent and width of the regurgitant jet, and categorized as none $(0)$, mild $(+1)$, moderate $(+2)$, moderate to severe $(+3)$, or severe $(+4)$

\section{Valvular Geometry}

To assess papillary tip displacement, the orthogonal distance from each PM tip marker to the least-squares mitral annular plane at the end-systole was calculated before and during acute ischemia. The least-squares method was used to describe the plane of the mitral annulus, because the native ovine mitral annulus is a complex, saddle-shaped structure that is nonplanar. We chose to reduce the annulus to a plane, to better describe the position of the PM tips relative to the mitral annulus, because this relationship has an important influence on leaflet edge position and valvular competence. Similarly, the distance in 3D space between each PM tip and the midseptal annulus (annular "saddle horn," marker \#21 in Figure 1) was calculated. The midseptal annulus was chosen because it is least sensitive to ischemic changes, and it has been extensively used as an echocardiographic landmark in clinical studies. We chose to represent PM tip displacements before and during ischemia as distances in 3D space, to permit a coordinate-free analysis of the geometric perturbations of the subvalvular apparatus. Leaflet edge displacement was represented as the orthogonal distance of each leaflet edge marker to the least-squares annular plane at end-systole.

\section{Statistical Analysis}

All data are reported as mean $\pm 1 \mathrm{SD}$. Data were compared using the Student $t$ test for paired observations.

\section{RESULTS}

The average weight of the animals was $74 \pm 11 \mathrm{~kg}$. The mean duration of acute circumflex coronary artery occlusion that was needed to induce IMR averaged $163 \pm 75$ seconds. Hemodynamic parameters and the degree of mitral insufficiency before and during IMR are summarized in Table 1. Acute ischemia significantly reduced left ventricular systolic pressure and performance, while heart rate remained unchanged. No episodes of atrial fibrillation or ventricular arrhythmias were observed during, before, or after acute ischemia. Mitral regurgitation increased from a baseline of trace-mild to the moderate-severe level.

Papillary muscle displacements relative to the mitral annular plane and the annular "saddle horn" are illustrated in Table 2. During acute ischemia, the distance of the 3 anterior PM heads from the annular plane did not change. Two of the 3 posterior PM heads moved closer to the annular 


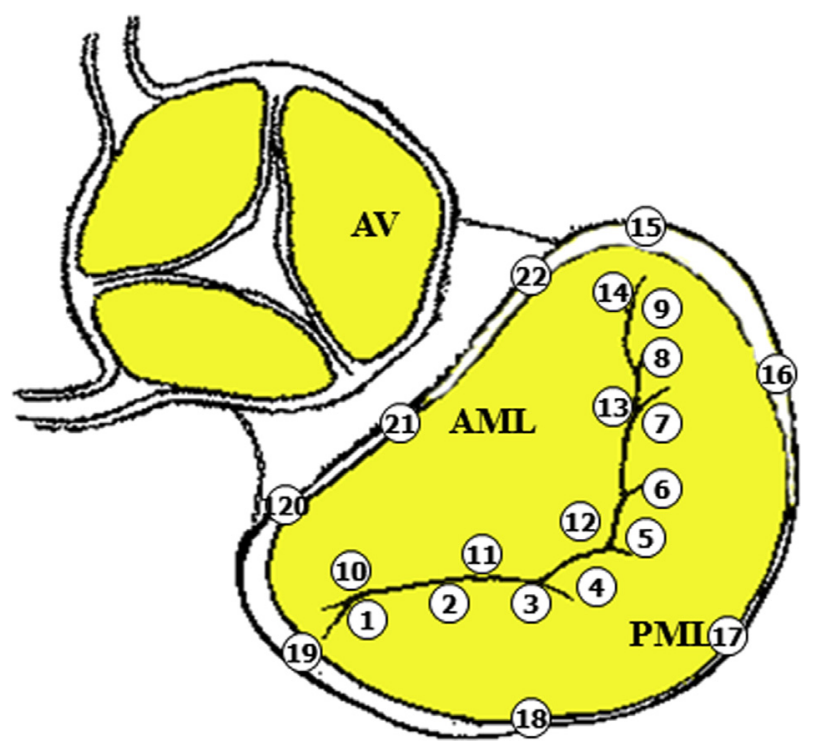

FIGURE 1. Schematic array of annular and leaflet myocardial markers implanted in the study animals. Nine (1-9) markers were placed on the PML edge, 5 (10-14) on the AML edge, and 8 (15-22) around the mitral annulus. $A V$, Aortic valve; $A M L$, anterior mitral leaflet; $P M L$, posterior mitral leaflet.

plane, and 1 did not change position. Displacement of PM heads away from the annulus, ie, apical displacement, was never observed. In addition, the distance from the anterior PM tips to the midseptal annulus did not change with IMR, underscoring its stable geometry during acute posterolateral ischemia. On the other hand, all 3 heads of the posterior PM moved away from the annular "saddle horn," representing lateral and posterior displacement of the posterior PM associated with IMR.

Displacements of leaflet edge markers of the anterior and posterior mitral leaflet edges from the mitral annular plane are illustrated in Figure 3. Apical tethering of the posterior leaflet in the central region was observed, and relative prolapse was seen near the posterior commissure. Anterior leaflet edge geometry remained essentially unchanged during acute ischemia, although a small degree of relative prolapse was observed near the posterior commissure. Bileaflet prolapse near the posterior commissure, although not intuitive, is consistent with the posterior PM displacement, toward the mitral annulus, that was observed during IMR.

\section{DISCUSSION}

Apical leaflet tethering is the vector sum of geometric perturbations that are associated with postinfarction ventricular remodeling leading to IMR. However, the precise alterations in the subvalvular apparatus that result in leaflet malcoaptation have not been clearly identified. Many reports in the literature equate apical leaflet tethering with apical PM displacement, but this equivalency may be erroneous. The present study, using the most extensive marking of leaflet edges and PMs to date, revealed no apical PM displacement during acute ovine IMR.

Ischemic mitral regurgitation represents a surgical challenge, as current reparative techniques centered on reductive annuloplasty have yielded suboptimal results. ${ }^{2}$ Our understanding of the pathophysiology of IMR has increased over the past decade, from the results of multiple clinical and experimental studies, ${ }^{1}$ yet this has not translated into clear clinical benefit. New surgical strategies have been focused on the subvalvular apparatus and PM repositioning, with or without ring annuloplasty. ${ }^{4,13-15}$ However, more refined geometric data are needed to further guide the evolution of these novel approaches.

The current experimental study revealed that apical displacement of any of the marked 6 PM tips was not observed during acute ovine IMR. Papillary muscle "tethering" distance, most often defined echocardiographically as the distance between the PM tips and the midseptal annulus, has been reported to be increased in association with IMR, by several investigators. ${ }^{5,16,17}$ Yet, this finding does not directly imply apical displacement of the papillary tips. This $2 \mathrm{D}$ distance represents the sum of $3 \mathrm{D}$ geometric perturbations in the subvalvular apparatus, and its increase does not describe the precise direction of PM displacement.

Furthermore, echocardiographic assessment cannot precisely discern different heads of the PMs as in the current study. Here, posterior PM "tethering" was additionally observed as the posterior PM moved away from the midseptal annulus, but without apical displacement away from the mitral annulus. These findings suggest that lateral and posterior displacement of the posterior PM is chiefly responsible for the increase in this distance. Prior studies from our laboratory in acute IMR, using both sheep and dogs, support these data. ${ }^{8,18}$ Similar results have been reported by Tibayan and colleagues ${ }^{7}$ in a model of ovine chronic IMR. Predominant postero-lateral displacement of the posterior PM tip was observed in that study in association with chronic IMR at 6 weeks, although a small apical displacement vector was additionally seen.

All the studies mentioned here so far used an internal coordinate system to quantitate the $3 \mathrm{D}$ geometric displacements of the subvalvular apparatus. The basal displacement of the posterior PM and relative leaflet prolapse near the posterior commissure are consistent with decreased tension in the chordae emanating from the weakened ischemic posterior PM, as described by Nielsen and colleagues ${ }^{19}$ in a porcine model of acute IMR. Thus, the heterogeneous changes in leaflet geometry seen in the present experiment are consistent with PM tip displacements, and multiple corroborative studies revealing that IMR can be associated with tethered ${ }^{5,20}$ or prolapsed ${ }^{21}$ leaflet motion, with symmetric or asymmetric leaflet deformity. ${ }^{20,22,23}$ 


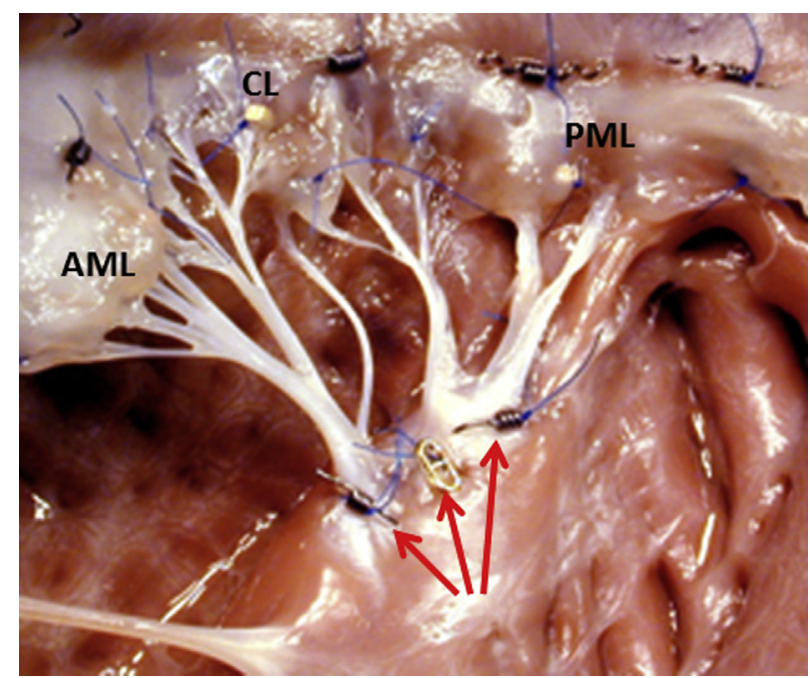

FIGURE 2. Intraoperative photograph of papillary tip markers (red arrows) on the posterior papillary muscle. $A M L$, Anterior mitral leaflet; $C L$, commissural leaflet; $P M L$, posterior mitral leaflet.

The results of the current study may have surgical implications for subvalvular interventions aimed at addressing IMR. These data suggest that repositioning of PMs toward the mitral annulus may not be efficacious in relieving IMR, as has indeed been observed in an experimental study by Langer and colleages. ${ }^{3}$ They found that repositioning the posterior PM toward the posterior commissure, and hence toward the annular plane, failed to decrease acute IMR. Based on the current findings, one may expect that such an intervention would exacerbate leaflet prolapse near the posterior commissure while failing to correct leaflet tethering near the valve center. Although apical displacement of PM tips was not observed in this study, apical leaflet tethering was demonstrated, consistent with multiple prior studies, as just discussed.

Associated with altered leaflet geometry was a significant increase in the distance of the posterior PM tips to the septal annulus. The increase in this distance, which most likely reflects lateral and posterior displacement of posterior PM during acute ischemia, is what seems to be the central subvalvular perturbation responsible for acute IMR. Thus, leaflet tethering can arise without apical displacement of the PM tips if significant postero-lateral PM dislocation occurs, with no associated chordal remodeling. Indeed, a recent comprehensive study involving magnetic resonance imaging evaluation of patients with IMR, supplemented with an experimental IMR animal model and computational analysis, revealed that loss of lateral shortening of the interpapillary distance may be central to the pathogenesis of IMR. $^{24}$

Experimental surgical interventions that relocate the posterior PM toward the septum, such as a cinching stitch ${ }^{25}$ or inflating balloon, ${ }^{26}$ have shown promise in controlling IMR.
TABLE 1. Hemodynamic parameters and the degree of mitral insufficiency before and during ischemic mitral regurgitation

\begin{tabular}{lcc}
\hline \multicolumn{1}{c}{ Parameters } & Pre-ischemia & Ischemia \\
\hline Heart rate (beats per min) & $92 \pm 9$ & $86 \pm 14$ \\
$\mathrm{dP}_{\mathrm{dt}}$ max $(\mathrm{mm} \mathrm{Hg} / \mathrm{sec})$ & $1835 \pm 587$ & $1132 \pm 257^{*}$ \\
$\mathrm{LVESP}(\mathrm{mm} \mathrm{Hg})$ & $75 \pm 11$ & $52 \pm 5^{*}$ \\
$\mathrm{LVEDP}(\mathrm{mm} \mathrm{Hg})$ & $19 \pm 6$ & $35 \pm 7^{*}$ \\
$\mathrm{LVP}_{\max }(\mathrm{mm} \mathrm{Hg})$ & $112 \pm 10$ & $84 \pm 7^{*}$ \\
$\mathrm{MR}(+0-4)$ & $0.7 \pm 0.3$ & $2.7 \pm 0.5^{*}$ \\
\hline Data are presented as mean \pm SD. $d P / d t_{\max }$, Maximum positive rate of change of LV \\
pressure; LVESP, LV end-systolic pressure; $L V E D P$, LV end-diastolic pressure; \\
$L V P_{\max }$, maximum LV pressure; $M R$, mitral regurgitation (see scale in text). \\
$* P<.05$ versus ischemia, by Student $t$ test for paired comparisons.
\end{tabular}

Repositioning of the posterior PM with an externally adjusted chord, anchored at the fibrous trigone as an adjunct to ring annuloplasty, has now been used in additional clinical applications. ${ }^{13}$ In 30 patients with severe IMR, and a high risk for recurrence with conventional repair, as evidenced by a leaflet tenting height of $>10 \mathrm{~mm}$, an impressive $94 \%$ freedom from $\geq$ grade 2 IMR was observed after 2 years, along with significant ventricular remodeling. The efficacy of these interventions supports the findings of the current study.

Owing to disappointing results of isolated ring annuloplasty in the treatment of IMR, ${ }^{2}$ recent studies have refocused attention on subvalvular ${ }^{27}$ and leaflet ${ }^{28}$ interventions to augment annular reduction. Furthermore, preoperative leaflet tethering symmetry has been shown to predict recurrent IMR after ring annuloplsty. ${ }^{29}$ These data underscore the need for more detailed characterization of PM geometry to guide surgical technique and prognosis in the treatment of IMR. In this context, the current study provides valuable information, yet clinical validation is still needed.

\section{Limitations}

The results of the current study must be viewed in the context of several experimental limitations. This study was performed in an acute ischemic model, thereby limiting clinical extrapolation. However, the study offers insight into the clinical problem of IMR and provides guiding data for possible surgical interventions. The acute nature of the study does not account for leaflet and chordal remodeling that may modulate the effect of subvalvular geometry on leaflet tethering, ${ }^{30,31}$ yet current findings are consistent with prior chronic experimental animal studies. ${ }^{7}$ The acute, open-chest model is suboptimal, yet it provides valuable insight into the mechanism of IMR, albeit not in a clinically pertinent model.

Based on our past experiments, we have found that geometric perturbations associated with ovine acute IMR are very similar to those observed in chronic ovine IMR, although the magnitude of alteration differs. The current data will need validation in a chronic model, which we 
TABLE 2. Papillary muscle displacements relative to the mitral annular plane and the annular "saddle horn"

\begin{tabular}{|c|c|c|}
\hline \multicolumn{3}{|c|}{ Displacement (cm) } \\
\hline Papillary muscle & Pre-ischemia & Ischemia \\
\hline \multicolumn{3}{|l|}{ APM-MA } \\
\hline $\mathrm{APM}_{\mathrm{AML}}$ & $2.59 \pm 0.40$ & $2.62 \pm 0.36$ \\
\hline $\mathrm{APM}_{\mathrm{CM}}$ & $2.18 \pm 0.37$ & $2.20 \pm 0.38$ \\
\hline $\mathrm{APM}_{\mathrm{PML}}$ & $2.26 \pm 0.31$ & $2.32 \pm 0.29$ \\
\hline \multicolumn{3}{|l|}{ PPM-MA } \\
\hline $\mathrm{PPM}_{\mathrm{AML}}$ & $2.79 \pm 0.42$ & $2.66 \pm 0.36^{*}$ \\
\hline $\mathrm{PPM}_{\mathrm{CM}}$ & $2.34 \pm 0.46$ & $2.20 \pm 0.40^{*}$ \\
\hline $\mathrm{PPM}_{\mathrm{PML}}$ & $2.20 \pm 0.40$ & $2.13 \pm 0.34$ \\
\hline \multicolumn{3}{|l|}{ APM-SH } \\
\hline $\mathrm{APM}_{\mathrm{AML}}$ & $3.62 \pm 0.17$ & $3.71 \pm 0.08$ \\
\hline $\mathrm{APM}_{\mathrm{CM}}$ & $3.61 \pm 0.25$ & $3.76 \pm 0.39$ \\
\hline $\mathrm{APM}_{\mathrm{PML}}$ & $3.73 \pm 0.30$ & $4.08 \pm 060$ \\
\hline \multicolumn{3}{|l|}{ PPM-SH } \\
\hline $\mathrm{PPM}_{\mathrm{AML}}$ & $3.92 \pm 0.54$ & $4.11 \pm 0.39^{*}$ \\
\hline $\mathrm{PPM}_{\mathrm{CM}}$ & $3.72 \pm 0.49$ & $4.10 \pm 0.28 *$ \\
\hline $\mathrm{PPM}_{\mathrm{PML}}$ & $3.68 \pm 0.41$ & $4.10 \pm 0.22^{*}$ \\
\hline
\end{tabular}

Data are presented as mean $\pm \mathrm{SD}$. $A P M$, Anterior papillary muscle; $M A$, mitral annular plane; $A M L$, anterior mitral leaflet; $C M$, commissural leaflet; $P M L$, posterior mitral leaflet; $P P M$, posterior papillary muscle; $S H$, annular "saddle horn" (midseptal annulus). $* P<.05$ versus ischemia, by Student $t$ test for paired comparisons.

are planning to undertake in the future. Owing to the technical limitations of a dense mitral leaflet marker array, we did not place left ventricular markers, and therefore, no information regarding left ventricular volumes was recorded in this experiment.

We chose to focus on the regional perturbations in leaflet and PM geometry, and therefore chose a dense array for these structures, while ignoring ventricular dynamics. As a result, the effect of acute changes in left ventricular volume on IMR could not be evaluated. We did not monitor central venous pressure, or left atrial size, before or during induction of left ventricular ischemia. However, all animals were monitored with transesophageal echocardiography during data acquisition, and echocardiographic assessment of biventricular function and volume were performed at the outset.

Imaging-based assessment of volume status, although not optimal, was felt to be sufficient for standardization of hemodynamics in this acute experimental setup. On the other hand, our multiple prior studies, both acute and chronic, in the same animal model, have explored ventricular geometry and dynamics during acute and chronic posterolateral left ventricular ischemia. Another possibility is that the sutured markers affected leaflet geometry, but this seems unlikely because they are very small (aggregate mass $=20 \pm 6 \mathrm{mg}$ ). Furthermore, the mass effect of leaflet markers is carried across the experimental intervention and should affect baseline and experimental data equally.

Additionally, species differences in PM blood supply may further limit the extrapolation of these results to the

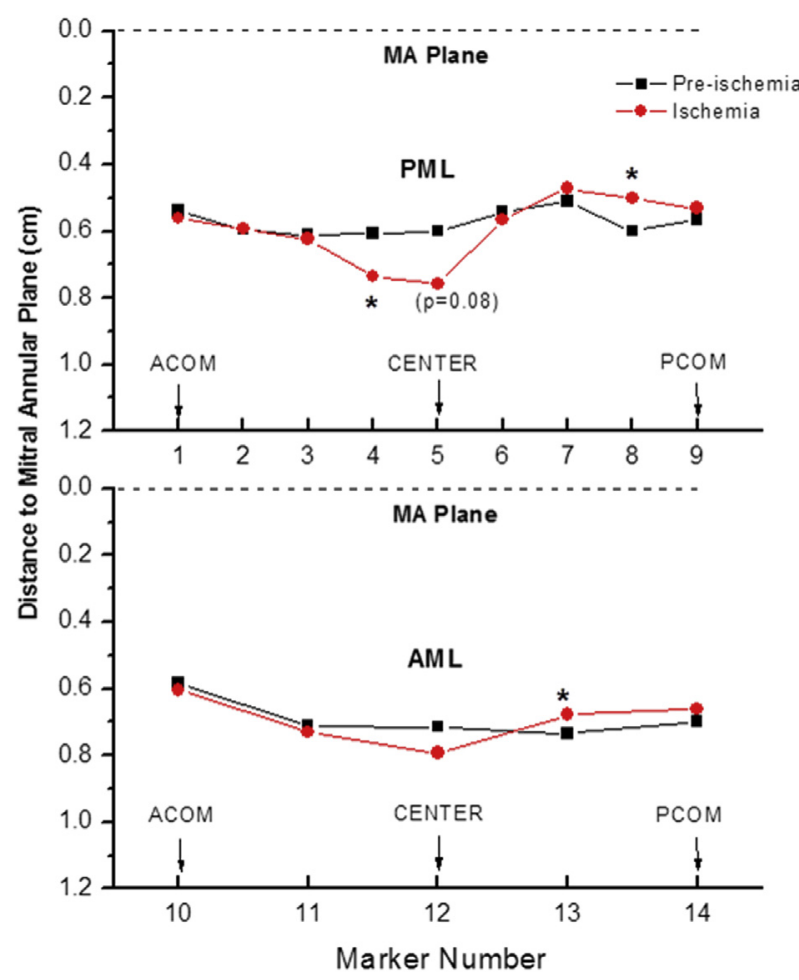

FIGURE 3. Mean displacements (cm) of the PML (top) and AML (bottom) markers relative to the MA before (squares) and during (circles) induction of acute posterolateral ischemia. Marker numbers corresponding to each leaflet location are shown on the $\mathrm{y}$-axis. CENTER $=$ valve center. $M A$, Mitral annular; $P M L$, posterior mitral leaflet; $A C O M$, anterior mitral commissure; $P C O M$, posterior mitral commissure; $A M L$, anterior mitral leaflet. $* P<.05$ versus ischemia.

human clinical condition. ${ }^{32}$ Sheep posterior PM blood supply is mainly derived from the circumflex system, ${ }^{33}$ whereas in humans, it is supplied mainly by branches of the right coronary artery. ${ }^{34}$ Furthermore, human inter-PM distance, and papillary to annular distance, vary greatly in healthy subjects, ${ }^{35}$ yet these parameters have not been investigated on a broad basis in healthy adult sheep. Any clinical inferences derived from our acute data must be interpreted in light of these anatomic differences.

\section{CONCLUSIONS}

Optimal surgical treatment of IMR needs further refinement, which can be guided only by more-precise knowledge of its pathophysiology. The present study presents the most detailed description of multiple PM head positions during acute IMR, yet no apical PM displacement was observed. This work supports subvalvular surgical interventions that aim to relocate the posterior PM toward the septum, while suggesting that basal relocation may not be efficacious. Further chronic data from experimental and clinical studies are needed to better define the magnitude and direction of PM relocation that is needed to reliably and durably treat IMR. 


\section{Conflict of Interest Statement}

Authors have nothing to disclose with regard to commercial support.

\section{References}

1. Levine RA, Schwammenthal E. Ischemic mitral regurgitation on the threshold of a solution: from paradoxes to unifying concepts. Circulation. 2005;112:745-58.

2. McGee EC, Gillinov AM, Blackstone EH, Rajeswaran J, Cohen G, Najam F, et al. Recurrent mitral regurgitation after annuloplasty for functional ischemic mitral regurgitation. J Thorac Cardiovasc Surg. 2004;128:916-24.

3. Langer F, Rodriguez F, Ortiz S, Cheng A, Nguyen TC, Zasio MK, et al. Subvalvular repair: the key to repairing ischemic mitral regurgitation? Circulation. 2005; 112:I383-9.

4. Hvass U, Joudinaud T. The papillary muscle sling for ischemic mitral regurgitation. J Thorac Cardiovasc Surg. 2010;139:418-23.

5. Yiu SF, Enriquez-Sarano M, Tribouilloy C, Seward JB, Tajik AJ. Determinants of the degree of functional mitral regurgitation in patients with systolic left ventricular dysfunction: a quantitative clinical study. Circulation. 2000;102:1400-6.

6. Agricola E, Oppizzi M, Pisani M, Meris A, Maisano F, Margonato A. Ischemic mitral regurgitation: mechanisms and echocardiographic classification. Eur J Echocardiogr. 2008:9:207-21.

7. Tibayan FA, Rodriguez F, Zasio MK, Bailey L, Liang D, Daughters GT, et al. Geometric distortions of the mitral valvular-ventricular complex in chronic ischemic mitral regurgitation. Circulation. 2003;108(Suppl 1):II116-21.

8. Lai DT, Timek TA, Tibayan FA, Green GR, Daughters GT, Liang D, et al. The effects of mitral annuloplasty rings on mitral valve complex 3-D geometry during acute left ventricular ischemia. Eur J Cardiothorac Surg. 2002;22:808-16.

9. Glasson JR, Komeda M, Daughters GT, Bolger AF, MacIsaac A, Oesterle SN, et al. Early systolic mitral leaflet "loitering" during acute ischemic mitral regurgitation. J Thorac Cardiovasc Surg. 1998;116:193-205.

10. Glasson JR, Komeda M, Daughters GT, Foppiano LE, Bolger AF, Tye TL, et al. Most ovine mitral annular 3-D size reduction occurs before ventricular systole and is abolished with ventricular pacing. Circulation. 1997;96:II115-23.

11. Niczyporuk MA, Miller DC. Automatic tracking and digitization of multiple radiopaque myocardial markers. Comput Biomed Res. 1991;24:129-42.

12. Daughters GT, Sanders WJ, Miller DC, Schwarzkopf A, Mead CW, Ingels NBJ. A comparison of two analytical systems for 3-D reconstruction from biplane videoradiograms. IEEE Comput Cardiol. 1989;15:79-82.

13. Langer F, Kunihara T, Hell K, Schramm R, Schmidt KI, Aicher D, et al. RING+STRING: successful repair technique for ischemic mitral regurgitation with severe leaflet tethering. Circulation. 2009;120(11 Suppl):S85-91.

14. Shudo Y, Matsumiya G, Sakaguchi T, Miyagawa S, Yoshikawa Y, Yamauchi T, et al. Assessment of changes in mitral valve configuration with multidetector computed tomography: impact of papillary muscle imbrication and ring annuloplasty. Circulation. 2010;122(11 Suppl):S29-36.

15. Borger MA, Murphy PM, Alam A, Fazel S, Maganti M, Armstrong S, et al. Initial results of chordal-cutting operation for ischemic mitral regurgitation. J Thorac Cardiovasc Surg. 2007;133:1483-92.

16. Uemura T, Otsuji Y, Nakashiki K, Yoshifuku S, Maki Y, Yu B, et al. Papillary muscle dysfunction attenuates ischemic mitral regurgitation in patients with localized basal inferior left ventricular remodeling: insights from tissue Doppler strain imaging. J Am Coll Cardiol. 2005;46:113-9.

17. Kumanohoso T, Otsuji Y, Yoshifuku S, Matsukida K, Koriyama C, Kisanuki A, et al. Mechanism of higher incidence of ischemic mitral regurgitation in patients with inferior myocardial infarction: quantitative analysis of left ventricular and mitral valve geometry in 103 patients with prior myocardial infarction. J Thorac Cardiovasc Surg. 2003;125:135-43.

18. Komeda M, Glasson JR, Bolger AF, Daughters GT II, MacIsaac A, Oesterle SN, et al. Geometric determinants of ischemic mitral regurgitation. Circulation. 1997;96:II-128-33.
19. Nielsen SL, Hansen SB, Nielsen KO, Nygaard H, Paulsen PK, Hasenkam JM Imbalanced chordal force distribution causes acute ischemic mitral regurgitation: mechanistic insights from chordae tendineae force measurements in pigs. $J$ Thorac Cardiovasc Surg. 2005;129:525-31.

20. Kwan J, Shiota T, Agler DA, Popović ZB, Qin JX, Gillinov MA, et al. Geometric differences of the mitral apparatus between ischemic and dilated cardiomyopathy with significant mitral regurgitation: real-time three-dimensional echocardiography study. Circulation. 2003;107:1135-40.

21. Jouan J, Tapia M, Lansac E, Acar C. Ischemic mitral valve prolapse: mechanisms and implications for valve repair. Eur J Cardiothorac Surg. 2004;26:1112-7.

22. Watanabe N, Ogasawara Y, Yamaura Y, Yamamoto K, Wada N, Kawamoto T, et al. Geometric differences of the mitral valve tenting between anterior and inferior myocardial infarction with significant ischemic mitral regurgitation: quantitation by novel software system with transthoracic real-time three-dimensional echocardiography. J Am Soc Echocardiogr. 2006;19:71-5.

23. Agricola E, Oppizzi M, Maisano F, De Bonis M, Schinkel AF, Torracca L, et al Echocardiographic classification of chronic ischemic mitral regurgitation caused by restricted motion according to tethering pattern. Eur J Echocardiogr. 2004;5: 326-34.

24. Kalra K, Wang Q, McIver BV, Shi W, Guyton RA, Sun W, et al. Tempora changes in interpapillary muscle dynamics as an active indicator of mitral valve and left ventricular interaction in ischemic mitral regurgitation. J Am Coll Cardiol. 2014;64:1867-79.

25. Timek TA, Lai DT, Liang D, Tibayan F, Langer F, Rodriguez F, et al. Effects of paracommissural septal-lateral annular cinching on acute ischemic mitral regurgitation. Circulation. 2004;110:II79-84.

26. Hung J, Guerrero JL, Handschumacher MD, Supple G, Sullivan S, Levine RA. Reverse ventricular remodeling reduces ischemic mitral regurgitation: echoguided device application in the beating heart. Circulation. 2002;106:2594-600

27. Szymanski C, Bel A, Cohen I, Touchot B, Handschumacher MD, Desnos M, et al Comprehensive annular and subvalvular repair of chronic ischemic mitral regurgitation improves long-term results with the least ventricular remodeling. $\mathrm{Circu}$ lation. 2012;126:2720-7.

28. Jassar AS, Minakawa M, Shuto T, Robb JD, Koomalsingh KJ, Levack MM, et al Posterior leaflet augmentation in ischemic mitral regurgitation increases leaflet coaptation and mobility. Ann Thorac Surg. 2012;94:1438-45.

29. van Garsse L, Gelsomino S, Cheriex E, Lucà F, Rao CM, Parise O, et al. Tethering symmetry reflects advanced left ventricular mechanical dyssynchrony in patient with ischemic mitral regurgitation undergoing restrictive mitral valve repair. Ann Thorac Surg. 2012;94:1418-28.

30. Tibayan FA, Rodriguez F, Langer F, Zasio MK, Bailey L, Liang D, et al. Increases in mitral leaflet radii of curvature with chronic ischemic mitral regurgitation. $J$ Heart Valve Dis. 2004;13:772-8.

31. Timek TA, Lai DT, Dagum P, Liang D, Daughters GT, Ingels NB Jr, et al. Mitra leaflet remodeling in dilated cardiomyopathy. Circulation. 2006;114:I518-23.

32. Walmsley R. Anatomy of human mitral valve in adult cadaver and comparative anatomy of the valve. Br Heart J. 1978;40:351-66.

33. Llaneras MR, Nance ML, Streicher JT, Lima JA, Savino JS, Bogen DK, et al. Large animal model of ischemic mitral regurgitation. Ann Thorac Surg. 1994; 57:432-9.

34. Rusu MD, Terescu CI, Niculescu V, Ionescu N, Vlad M. Considerations on the left papillary muscles microangioarchitecture. Rom J Morphol Embryol. 2006 47:63-6.

35. Sonne C, Sugeng L, Watanbe N, Weinert L, Saito K, Tsukiji M, et al. Age and body surface area dependency of mitral valve and papillary apparatus parameters: assessment by real time three dimensional echocardiography. Eur J Echocardiogr. 2009; 10:287-94.

Key Words: mitral valve, mitral valve repair, ischemic mitral regurgitation 